\title{
A interlocução entre poder público e cidadãos na proposta de gestão compartilhada da prefeitura de Belo Horizontel
}

The dialogue between government and citizens in the shared management proposal of the municipal government of Belo Horizonte

La interlocución entre el poder público y ciudadanos en la propuesta de gestión compartida de la municipalidad de Belo Horizonte

\section{Laura Nayara Pimenta}

- Doutoranda do Programa de Pós-graduação em Comunicação e Sociabilidade da Universidade Federal de Minas Gerais (UFMG)

- Mestre em Comunicação Social pela UFMG

- Graduação em Comunicação Social - Relações Públicas pelo Centro Universitário Newton Paiva, de Belo Horizonte

- Cocoordenadora do projeto de extensão "Suporte de comunicação do programa polo de integração da UFMG no Vale do Jequitinhonha"

- $\quad$ Pesquisadora integrante do grupo de pesquisa "Mobiliza" (CNPq/UFMG)

- E-mail: Lanapi05@gmail.com 


\section{Resumo}

0 presente artigo, síntese de nossa dissertação de mestrado, compreende, a partir do caso da Vila Jardim do Vale, de Belo Horizonte, como as interações comunicativas de uma comunidade proveniente de ocupação a tornam um público capaz de participar, aumentar sua potência cívica e, assim, influenciar a tomada de decisão do poder público, considerando um contexto dito de gestão compartilhada. Para isso, foram utilizadas observações sistemáticas, entrevistas em profundidade, pesquisa bibliográfica e análise documental.

PALAVRAS-CHAVE:COMUNICAÇÃOPÚBLICA•DESENHOSINSTITUCIONAIS•GESTÃOCOMPARTILHADA•ARTICULAÇÃOCOMUNITÁRIA•COMUNIDADE.

\section{Abstract}

This article, a summary of our master's thesis, comprises, based on the case of the district of Vila Jardim do Vale, in Belo Horizonte, how the communication interactions of a community that arose from unlawful occupation transforms it into a public that is able to participate, increase its civic power and thus influence the decisions of the public authorities, considering a context that is said to be of shared management. For this we used systematic observations, in-depth interviews and document analyses.

\section{KEYWORDS: PUBLIC COMMUNICATION •INSTITUTIONAL DESIGNS • SHARED MANAGEMENT • COMMUNITY ARTICULATION • COMMUNITY.}

\section{Resumen}

El presente artículo, síntesis de nuestra tesis de maestría, comprende, desde el caso de Vila Jardim do Vale, de la ciudad de Belo Horizonte, cómo las interacciones comunicativas de una comunidad proveniente de la ocupación la convirtieron en un público con capacidad de participar, ampliar su potencia cívica y, así, influenciar en la toma de decisiones del poder público, teniendo en cuenta un contexto denominado de gestión compartida. Para ello, se utilizaron observaciones sistemáticas, entrevistas en profundidad, investigación bibliográfica y análisis documental. 
$A^{2}$

partir da constatação da necessidade de mudanças em seu arranjo organizacional para melhorar a performance e estabelecer novos rumos para a administração municipal, e considerando a premissa de participação social como mister, a Prefeitura Municipal de Belo Horizonte criou, em 2011, a Secretaria Municipal Adjunta de Gestão Compartilhada (SMAGC). O boletim Gestão compartilhada(PBH, 2011, p.1) declara que a gestão compartilhada "deve ser uma forma de radicalizar a democracia, ampliando as possibilidades de participação e controle social na gestão daquilo que é de interesse público". Deste modo, a prefeitura acredita estar estimulando a mobilização social, a capacitação dos representantes da sociedade e a criação de novos espaços participativos dialógicos, que deveriam ampliar a cooperação institucional e proporcionar maior transparência nas atividades governamentais, por meio das secretarias, gerências e autarquias que a integram.

Segundo Avritzer (2008), o êxito do controle social proposto pelo sistema de gestão compartilhada está intrinsecamente relacionado à maneira como se articulam o desenho institucional das instâncias participativas - intervenções propositais e deliberadas que permitem planejar, de forma prospectiva, normas e arranjos para os mais diversos tipos de instituições - e a organização da sociedade civil para se inserir nesses canais. Isto é, cada desenho orienta e configura modos específicos de interação entre poder público e cidadãos que definem possibilidades e limites para o exercício da influência comunitária por meio das instâncias participativas. Mesmo com os limites a ela impostos, essa influência só é possível quando uma comunidade aumenta sua potência cívica por meio das interações comunicativas entre seus membros -interações estas que permitem a tessitura da coletividade e de suas reivindicações, afetando, consequentemente, a qualidade da participação.

Casos como o da Vila Jardim do Vale, um dos 73 bairros da Regional Barreiro de Belo Horizonte, demonstram como os seus moradores precisaram se organizar, e ainda precisam, para conseguir se fazer ouvir nessas instâncias participativas e assim alcançar alguma melhoria na infraestrutura básica da vila mediante influência na tomada de decisão do poder público. Surgida de uma ocupação irregular iniciada em 1996, em um terreno abandonado por uma empreiteira que não pagava os impostos devidos à prefeitura, a Vila Jardim do Vale enfrentou grandes dificuldades desde a sua ocupação. Por ser um local invadido, a população lá residente não tinha coleta de resíduos sólidos, saneamento básico, ligação legal com a rede elétrica, entre outros serviços básicos.

Diante desse cenário, o objetivo geral desse trabalho é compreender, a partir do caso empírico da Vila Jardim do Vale, como as interações comunicativas de uma comunidade proveniente de ocupação a constituem como um público capaz de participar, aumentar sua potência cívica e, assim, influenciar a tomada de decisão do poder público, considerando um contexto dito de gestão compartilhada.

Assim, iniciamos o artigo discutindo o processo de comunicação pública, enquanto interlocução entre poder público e cidadãos, além de evidenciar as interfaces deste com o sistema de gestão compartilhada. Em seguida, analisamos como os desenhos institucionais dessa nova forma de gestão conformam o relacionamento entre governo e sociedade civil, influindo profundamente na necessidade de mobilização e articulação das comunidades que desejam ser inseridas nessa interação institucional. Após essas discussões teóricas, as duas últimas seções abordam os aspectos mais empíricos da pesquisa, como a apresentação dos casos da Prefeitura de Belo Horizonte e da Vila Jardim do Vale, além da análise do relacionamento entre elas.

\section{COMUNICAÇÃO PÚBLICA EM PROCESSOS DE GESTÃO COMPARTILHADA}

O conceito de comunicação pública implica várias vertentes e significações, que vão desde premissas mais simplistas ligadas às técnicas comunicativas governamentais até as relações mais subjetivas e abstratas entre os cidadãos e o poder público. 
Não pretendemos detalhar todas as vertentes teóricas sobre a comunicação pública neste artigo, mas nos interessamos por aquelas que nos esclarecem as formas como os cidadãos se articulam para permear um contexto comunicativo cercado de normas, construindo uma possível interlocução entre as partes.

Dentre as múltiplas dimensões da comunicação pública que podem ser encontradas na literatura, destacamos três que nos permitem elucidar como esse processo comunicacional se dá em um cenário normativo de gestão compartilhada²: (a) comunicação do poder público "para" e "com" os cidadãos (Koçouski, 2012; Kunsch, 2012; Brandão, 2009; Zémor, 1995); (b) comunicação pública como espaço de circulação estratégica de temas de interesse público (Weber, 2007; Duarte, 2011); (c) comunicação constituída no espaço público e veiculada pela (ou para) a opinião pública (Esteves, 2011). Cada uma dessas dimensões apresenta limites e possibilidades peculiares que dizem um pouco sobre cada faceta do processo de comunicação pública. Isso nos leva a acreditar que tal processo se constitui como um complexo de interações específicas e amplas que não se excluem mutuamente, pelo contrário, se permeiam.

Desse modo, não podemos nos ater apenas a uma ou outra dessas dimensões para compreender como o processo de comunicação pública se dá no sistema de gestão compartilhada. Isso porque, ao mesmo tempo em que as interlocuções que ocorrem nesse sistema demandam condições de abertura, de visibilidade e publicidade dos debates, constituindo uma dinâmica ampla, elas também se conformam ao desenho dos espaços de participação, revestindo-se de institucionalidade. Não obstante, a comunicação pública também tem uma interface institucional que dá forma à interação das partes envolvidas na interlocução. A institucionalidade dos canais participativos e fóruns de interação que o poder público adota também conformam a ação da população, interferindo na organização e articulação de grupos e de comunidades que pretendem se inserir nesse contexto e ganhar condições de interlocução.

Isto posto, ratificamos que o processo amplo e aberto da comunicação pública se orienta e formata conforme os limites impostos por esse desenho. Esses limites podem demandar uma comunicação que seja meramente informativa ou possibilitar melhores meios para estimular a participação, mantendo as condições essenciais de publicidade das instâncias participativas.

Contudo, cabe ressaltar que a conformação da comunicação aos desenhos institucionais não é algo construído ingenuamente. Cada dimensão desses arranjos é pensada pelos governantes com o intuito de formatar uma especificidade de comunicação e participação para aquele canal, seja para dizer que possibilitam uma interlocução entre Estado e cidadãos tendo em vista o controle social ou para efetivamente gerar uma interação qualificada que permita que a tomada de decisão seja influenciada pela sociedade civil. Para tentarmos compreender essa dinâmica institucional que a gestão compartilhada incita, a próxima seção aborda os aspectos conceituais de seu modelo e as múltiplas dimensões dos desenhos institucionais contemplados por ele.

\section{GESTÃO COMPARTILHADA E DESENHOS INSTITUCIONAIS}

Nos últimos anos, o termo gestão compartilhada tem sido bastante utilizado, principalmente em sentidos que convergem no fato de considerarem a participação dos interessados - clientes, usuários, cidadãos - na gestão de iniciativas públicas

2 A noção de gestão compartilhada-como trabalhada por Costa (2009), Torrecilha (2013) e outros autores - propõe um sistema que envolva cooperação, compartilhamento, transparência e protagonismo social como forma de promover o exercício democrático. 
ou privadas. Segundo Costa (2009), o termo é recorrente nos textos que se referem aos modelos de gestão adotados em programas de desenvolvimento regional, em bacias hidrográficas, escolas e projetos de ciência e tecnologia que valorizam o protagonismo local.

Registros pioneiros do uso do termo encontram-se na Política Nacional de Recursos Hídricos (PNRH), também conhecida como "Lei das águas" e no programa Escola Comunitária de Gestão Compartilhada, da Secretaria da Educação e Cultura do Estado do Tocantins (Nolêto, 2009). Em ambos os documentos o termo apareceu no ano 1997 e inaugurou a ideia de descentralização da gestão e de participação da comunidade nos processos de tomada de decisão das políticas públicas citadas. Ainda que estes tenham sido os primeiros registros do termo no Brasil, a noção de gestão compartilhada - baseada em princípios de intersetorialidade, descentralização da gestão e participação da comunidade - já estava presente nas diretrizes do Sistema Único de Saúde (SUS) desde a Lei no 8.080, de 19 de setembro de 1990 (Ministério da Saúde, 2007).

Além disso, o Estatuto da Cidade - Lei no 10.257/2001 - dedica alguns artigos à chamada gestão democrática da cidade, cujas disposições remetem a um conceito de gestão pública compromissada com o processo de participação social. Para Torrecilha (2013), estas noções do SUS e do Estatuto da Cidade se aproximam, guardadas as devidas proporções, do que é entendido atualmente por gestão compartilhada, uma vez que esta, para a autora, é a possibilidade de se criar um espaço de participação para obter os melhores objetivos, para tomar decisões sobre políticas públicas, demandar serviços públicos, financiamentos, execução financeira e gestão de pessoas, bem como a transparência nas atividades realizadas no território.

Já Costa (2009), argumenta que a noção de gestão compartilhada se refere a novos desenhos institucionais que "compartilham" algumas dimensões da gestão ou da realização de uma iniciativa de interesse comum. Para o autor, esses desenhos devem ser novos, pois precisam superar o tradicional modelo burocrático tendo em vista os princípios da legalidade, da isonomia, da participação e da cidadania. Diante disso, ele afirma que tais arranjos institucionais têm que solicitar maior cooperação intergovernamental, parcerias público-privadas, mobilização de organizações não-governamentais e controle social difuso, conformando um intrincado processo de comunicação que qualifique a tomada de decisão.

Diferenças à parte, o fato é que nas concepções citadas muito se fala de protagonismo social e em instâncias que permitam essa autoridade. Contudo, os canais que foram criados com esse pretexto, tais como os conhecemos hoje, apresentam desenhos institucionais que interferem substancialmente no potencial participativo dos mesmos. As variações nesses desenhos podem favorecer ou colocar obstáculos à qualidade dos processos participativos e deliberativos, assim como afetar a capacidade decisória e o funcionamento desses espaços.

Considerando essa diversidade dos canais participativos, Fung (2006) argumenta que três questões de desenho institucional são importantes para a compreensão do potencial e dos limites das formas participativas: quem participa; como são formadas e tomadas as decisões; e como estas decisões se vinculam às políticas públicas. Cada uma dessas dimensões traz uma série de espectros de valores que não detalharemos neste artigo, mas cabe ressaltar que a argumentação do autor considera que o potencial de interlocução de uma instância participativa está diretamente relacionado às possibilidades de influência ou intervenção dos atores nos processos decisórios, bem como ao alcance que essas decisões têm no cenário político. Outro ponto a ser analisado é a forma de acesso dos participantes a esses canais - se o processo é aberto ou ocorre por meio de representação, ou se contempla ambas as dimensões. 0 terceiro ponto a ser observado é o processo de tomada de decisão: se este ocorre por meio de um mecanismo agregativo ou se é de natureza deliberativa, ou se envolve ambas as dimensões (Fung, 2006).

Um problema importante em relação aos desenhos institucionais é perceber como as decisões que os participantes tomam se tornam políticas, bem como o potencial que eles têm para influenciar as autoridades institucionalizadas. Para 
Fung (2006), poucos são os mecanismos de participação que exercem o poder direto. De acordo com o autor, tal poder pode ser exercido em dois níveis: em uma situação de cogovernança ou em contextos de autoridade participativa direta. No caso da cogovernança, os cidadãos que participam se juntam com os funcionários em uma espécie de parceria para fazerem planos e políticas ou desenvolverem estratégias para a ação pública. Em um nível mais elevado, as instâncias participativas ocasionalmente exercem autoridade direta sobre as decisões ou recursos públicos, controlando, planejando ou implementando projetos de desenvolvimento local. Contudo, cabe ressaltar que ocasionalmente é possível que ocorra uma cogovernação ou uma autoridade direta por parte dos cidadãos, pois as relações de poder que permeiam a máquina estatal raramente permitem que se delegue a tomada de decisão ao público considerado leigo.

Mesmo com esses entraves, podemos considerar que a categoria de cogovernança de Fung está intrinsecamente relacionada ao discurso da proposta de gestão compartilhada de Belo Horizonte, que, para seus gestores, representa uma maneira de ampliar o diálogo, a parceria com a sociedade na hora de governar a cidade (PBH, 2011). Entretanto, Avritzer (2008) observa que o êxito desse sistema participativo não está somente ligado ao desenho institucional, mas sim à maneira como se articulam desenho institucional, organização da sociedade civil e vontade política de implantar arranjos participativos. Assim, a próxima seção abordará a questão da organização da comunitária frente a esses desenhos institucionais.

\section{ARTICULAÇÃO COMUNITÁRIA E INFLUÊNCIA EM CENÁRIOS DE GESTÃO COMPARTILHADA}

Antes de entrarmos na discussão de articulação comunitária propriamente dita, cabe ressaltar que os desenhos institucionais são objetos da ação humana, e não apenas incidem sobre essa ação. Eles são construções sociais, isto é, não se autorrealizam, mas são objetos de intervenções humanas, deliberadas ou não, que influem sobre a própria instituição criada. Portanto, podemos considerar que essas instituições resultam de processos de escolhas, decorrem da decisão e da ação humanas e correspondem a valores que são difundidos socialmente, o que as torna sensíveis aos atores que interagem no seu interior, no seu entorno e com elas. Nesse sentido, tanto podem incidir sobre a ação humana, quanto são objeto dessa ação.

Por serem produtos humanos, essas instituições não se constituem por acaso. Cada dimensão do desenho institucional dos canais participativos é pensada pelos gestores e políticos com a intenção de conformarem uma especificidade de participação para aquele canal, seja para dizer que permitem o controle social ou para efetivamente deixá-lo acontecer. Não obstante, a sociedade civil também tem condições de realizar mudanças, de influenciar aspectos do desenho. Tal influência só se torna possível quando os cidadãos, os membros da sociedade civil, for talecem seus laços de cooperação e solidariedade por meio das interações comunicativas, o que pode aumentar a potência cívica da sociedade, possibilitando uma participação qualificada nas instâncias disponibilizadas pelo poder público, o que permite maiores chances de respostas às suas reivindicações.

Contudo, essas influências não estão totalmente circunscritas às instâncias e aos canais formais de participação, pois os públicos buscam também outras formas de ação - de expressão - que extrapolam esses limites, mas podem incidir sobre a tomada de decisão segundo a permeabilidade das instituições às diversas demandas e em função e sua necessidade de accountability.

Diante disso, podemos elencar pelo menos três ações cabíveis para que os cidadãos se insiram nesse contexto e tentem alguma chance de interlocução. Uma dessas atitudes é a adequação dos cidadãos às normativas impostas pela instância, conhecendo seu funcionamento, as possibilidades que ela oferece, capacitando-se para a participação. Outra atitude, 
segundo Dryzek (2000), é a utilização de agentes "extraconstitucionais", tais como manifestações, boicotes, eventos midiáticos, entre outros, para promover uma influência direta no poder público, contornar os bloqueios gerados pelos desenhos institucionais, ou reivindicar a modificação desses desenhos. Além disso, os cidadãos podem utilizar parcerias com autoridades políticas do Poder Legislativo ou do próprio Executivo para tentar influenciar a modificação desses canais ou até mesmo alcançar seus objetivos mais rapidamente.

De posse desses elementos teóricos e perseguindo nosso objetivo de apreender empiricamente como uma comunidade proveniente de ocupação consegue influenciar a tomada de decisão do poder público, na próxima seção traçamos um panorama da estrutura e do discurso da proposta de gestão compartilhada da Prefeitura de Belo Horizonte, além de construirmos um painel do histórico e da organização comunitária da Vila Jardim do Vale.

\section{O CASO EM QUESTÃO: A PREFEITURA DE BELO HORIZONTE E A VILA JARDIM DO VALE}

Apresentada por seus gestores como a capital com maior histórico de participação cidadã na gestão pública, Belo Horizonte utiliza canais como o orçamento participativo, conferências, fóruns, audiências públicas, entre outros, na tentativa de melhorar a vida das pessoas. Tentando dar continuidade a esse histórico, a prefeitura criou, em 2011, a Secretaria Municipal Adjunta de Gestão Compartilhada (SMAGC), cujo objetivo é dinamizar, organizar, expandir e integrar todas as atuais formas de participação da cidade. Deste modo, ela acredita estar estimulando a mobilização social, a capacitação dos representantes da sociedade e a criação de novos espaços dialógicos, ampliando a cooperação institucional e proporcionando maior transparência nas atividades governamentais (Gestão Compartilhada, 2014).

Mas, afinal, como a Prefeitura de Belo Horizonte compreende a gestão compartilhada? De acordo com as informações obtidas em seu boletim Gestão compartilhada, esta "deve ser uma forma de radicalizar a democracia, ampliando as possibilidades de participação e controle social na gestão daquilo que é de interesse público" (PBH, 2011, p. 1). Para alcançar esses objetivos, a SMAGC apresenta uma localização estratégica no organograma da prefeitura, bem como possui uma organização interna tão complexa quanto o que ela deseja realizar. A secretaria está vinculada à Secretaria Municipal de Governo, que gerencia as atividades de apoio às ações políticas da administração municipal e assessora o município nas ações de representação política e em assuntos de natureza técnico-legislativa. 0 fato de a SMAGC estar vinculada a essa secretaria lhe confere uma posição estratégica dentro da estrutura da prefeitura, pois suas ações podem auxiliar e interferir no planejamento municipal, conferindo maior legitimidade às suas ações políticas.

Todavia, para que a atuação da SMAGC seja realmente estratégica, ela deve apresentar uma estrutura organizacional que lhe confira tal capacidade. Considerando o atual organograma institucional da secretaria, observamos que ela é composta por 33 gerências. Não entraremos aqui nas competências de cada gerência, mas, ao analisarmos as entrevistas que realizamos e os diversos decretos que regem a secretaria, algumas atribuições nos instigaram, principalmente por serem elementos em comum entre várias gerências e evidenciarem normativas da SMAGC que dizem sobre a interlocução que ela pretende instituir. Estas atribuições são: a) realização de diagnóstico sobre a situação da gestão participativa na cidade; b) capacitação e fortalecimento da representatividade comunitária; c) mobilização da sociedade para a participação.

A partir dessas atribuições, podemos concluir que, ao menos em princípio a Prefeitura de Belo Horizonte se mostra preocupada em qualificar e mobilizar os representantes da sociedade civil, de modo a fortalecer a cidadania e aprimorar a qualidade dos fóruns participativos e das discussões neles ocorridas. Por outro lado, fica evidente uma preocupação em construir 
um diagnóstico sobre as formas de participação existentes no município, para que se possa elaborar, posteriormente, um embasamento que paute a formatação de todos esses canais. Assim, fica claro que o próprio desenho fica sujeito a uma intervenção técnica especializada.

Outro ponto que devemos ressaltar é que na era da gestão compartilhada os canais participativos da Prefeitura de Belo Horizonte requerem uma ação transparente e que estabeleça uma interlocução entre a administração municipal e as organizações da sociedade civil. Além disso, para que a população saiba da existência desses canais, é preciso que a prefeitura desenvolva um processo de comunicação pública que não fique preso apenas ao caráter informativo. É preciso utilizar também estratégias de mobilização que sensibilizem a população.

Foi pensando nessa interação entre a SMAGC e as comunidades de Belo Horizonte, e perseguindo nosso objetivo, que trouxemos a Vila Jardim do Vale para a discussão. A história da vila apresenta elementos importantes que contribuem para elucidar algumas questões de articulação comunitária que interferem diretamente na consecução de nossos objetivos. Optamos por contá-la segundo os momentos que nos dizem mais sobre seus aspectos organizativos e conquistas coletivas. Assim, dividimos a "biografia" da vila em três grandes momentos: a) condição de clandestinidade e conflitos judiciais; b) conquista de direito à moradia e à participação; c) articulações comunitárias em busca de melhorias.

Tabela 1 - Biografia da Vila Jardim do Vale

\begin{tabular}{|c|c|c|}
\hline $\begin{array}{c}\text { Condição de clandestinidade } \\
\text { e conflitos judiciais }\end{array}$ & $\begin{array}{l}\text { Conquista de direito à } \\
\text { moradia e à participação }\end{array}$ & $\begin{array}{c}\text { Articulações comunitárias } \\
\text { em busca de melhorias }\end{array}$ \\
\hline $\begin{array}{l}1996 \text { - Ocupação de área não } \\
\text { habitada nas imediações do } \\
\text { Distrito Industrial do Vale do } \\
\text { Jatobá por cerca de } 50 \text { famílias; } \\
\text { - Lima Drumonnd Comércio e } \\
\text { Empreendimentos Ltda. ajuizou } \\
\text { uma ação de reintegração de } \\
\text { posse junto ao Poder Judiciário; } \\
\text { - Reações violentas à ocupação. } \\
\text { 1997 - Moradores da vila iniciam } \\
\text { organização coletiva para } \\
\text { combater a reintegração; } \\
\text { - Procuram o então vereador } \\
\text { Sérgio Ferrara para auxiliá-Los; } \\
\text { - Descoberta de dívidas da } \\
\text { empresa Lima Drumonnd com a } \\
\text { Prefeitura de Belo Horizonte. } \\
\text { 1998 - Decreto no 9.753 declarou a } \\
\text { área da Lima Drumonnd que estava } \\
\text { ocupada como de interesse social. } \\
\text { Assim, a empresa foi desapropriada. }\end{array}$ & $\begin{array}{l}1998 \text { - Com o Decreto no } 9.753 \\
\text { a ocupação ganhou o direito de } \\
\text { se constituir como bairro, mas } \\
\text { antes precisaria se organizar } \\
\text { para participar das disputas do } \\
\text { Orçamento Participativo (OP). } \\
1999 \text { - Líder comunitária liderou a } \\
\text { reivindicação e conquista da primeira } \\
\text { obra de manutenção: a construção } \\
\text { de um muro de gabião no Beco N; } \\
\text { - Eleição para a associação } \\
\text { comunitária; } \\
\text { - Conflitos com líder eleito } \\
\text { e divisão da associação. } \\
\text { 2000-2006 - O vereador Sérgio } \\
\text { Ferrara auxiliou a vila a conquistar } \\
\text { melhorias como asfaltamento, } \\
\text { ligações de esgoto e água, } \\
\text { implantação de energia elétrica. }\end{array}$ & $\begin{array}{l}2001 \text { - Moradores receberam } \\
\text { orientações sobre a necessidade } \\
\text { de investirem na participação no } \\
\text { processo de definição de aplicação } \\
\text { de verbas públicas do Orçamento } \\
\text { Participativo (OP) e na conquista de } \\
\text { recurso para elaborarem o Plano } \\
\text { Global Específico (PGE) da vila; } \\
\text { - Reabertura da associação } \\
\text { de moradores. } \\
\text { 2002 - Como grande articulação } \\
\text { comunitária, a vila alcançou } \\
\text { a captação de recursos por } \\
\text { meio do OP 2003/2004. } \\
\text { - Parceria com a Regional do Barreiro } \\
\text { e adesão da associação ao "Chapão" } \\
\text { - união de várias associações de } \\
\text { moradores de bairros da região - } \\
\text { impulsionou participação da vila } \\
\text { nas instâncias participativas da } \\
\text { Prefeitura de Belo Horizonte. }\end{array}$ \\
\hline
\end{tabular}

Fonte: Tabela elaborada pela autora. 
Com base no exposto, pudemos perceber a complexidade da proposta de gestão compartilhada da Prefeitura de Belo Horizonte e um pouco da organização comunitária da Vila Jardim do Vale. Todavia, para esclarecermos as interações comunicativas que configuram a vila como um público capaz de influenciar a tomada de decisão do poder público frente à proposta da SMAGC, dedicaremos a próxima seção às análises dos desenhos institucionais de três instâncias participativas, bem como das atuais ações mobilizadoras e articuladoras da comunidade Jardim do Vale para estabelecer uma relação institucional com a prefeitura.

\section{ANÁLISE DOS DESENHOS INSTITUCIONAIS, DA INFLUÊNCIA COMUNICATIVA E SEUS IMPASSES}

Para procedermos às análises propostas na seção anterior, utilizamos os elementos do "cubo tridimensional da democracia" de Archon Fung (Figura 1) para compararmos a "visão oficial" e a "visão cotidiana" dos desenhos institucionais das três instâncias participativas da Prefeitura de Belo Horizonte em que a Vila Jardim do Vale têm maior participação (Nudec, CLSVJ, Comforça) $)^{3}$. Empreendemos essa análise para que pudéssemos perceber as diferenças existentes entre a visão oficial dos desenhos institucionais, ou seja, aquela tida pelos burocratas do poder público, e a visão cotidiana do funcionamento desses desenhos, evidenciada pelo ponto de vista dos participantes e de nossas observações. Além disso, ao dispormos os mecanismos que estamos analisando no cubo, pudemos perceber as possibilidades de comunicação e de influência que ele contempla (ou não), para ver como isso incide na organização da vila.

Figura 1 - Cubo tridimensional da democracia

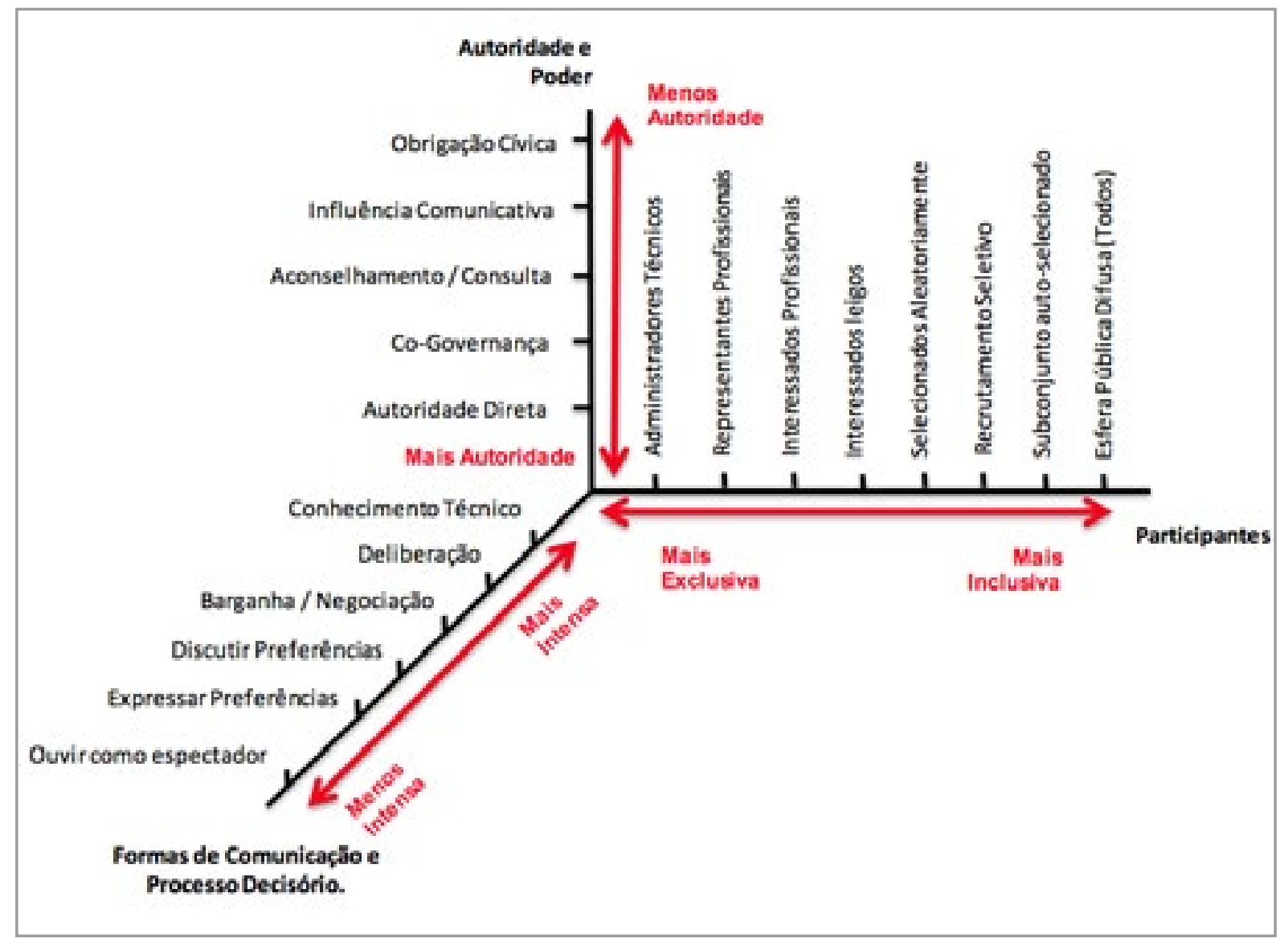

Fonte: Fung (2006).

3 Estas instâncias são o Núcleo Comunitário de Defesa Civil (Nudec), em que a vila tem seis representantes; a Comissão Local de Saúde do Vale do Jatobá (CLSVJ), que também é integrada por seis lideranças da vila; e a Comissão de Acompanhamento e Fiscalização da Execução do Orçamento Participativo (Comforça), que conta com cinco delegados da Jardim do Vale. 
Assim, chegamos às seguintes figuras, que retratam os desenhos do Nudec, da CLSVJ e da Comforça:

Figura 2 - Desenho institucional do Nudec Jardim do Vale

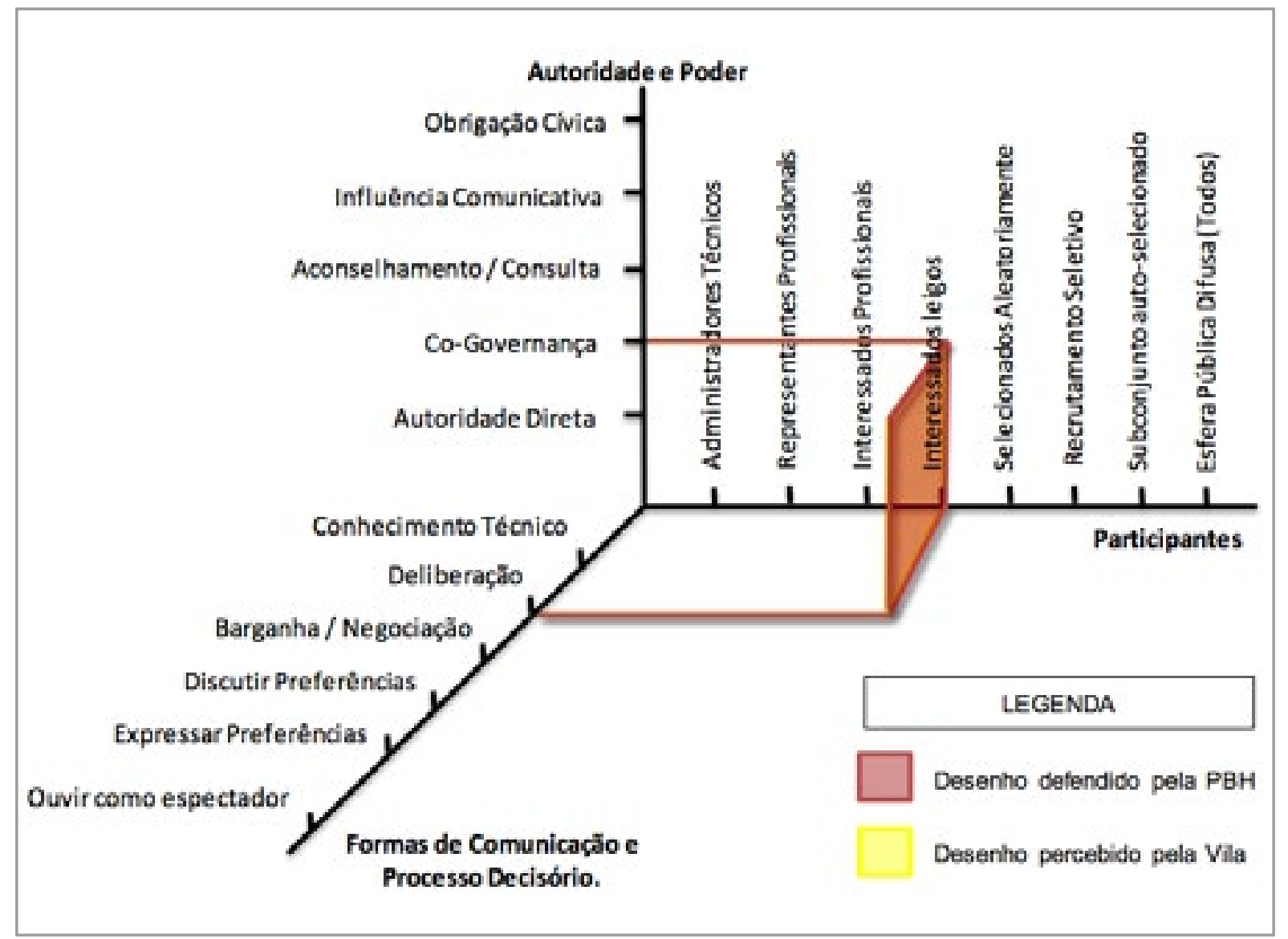

Fonte: Elaborada pela autora.

Figura 3 - Desenho institucional do CLSVJ

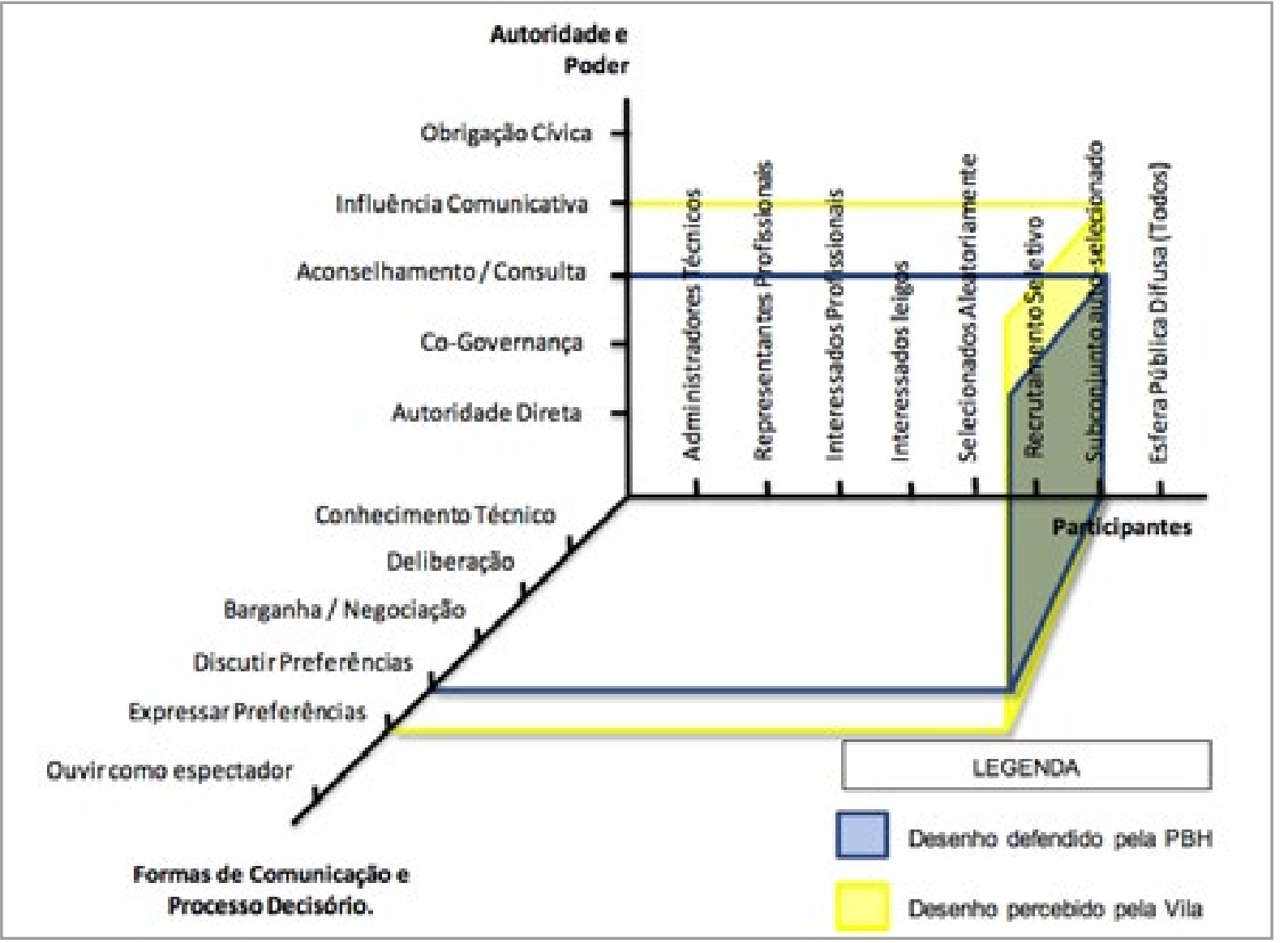

Fonte: Elaborada pela autora. 
Figura 4 - Desenho institucional da Comforça

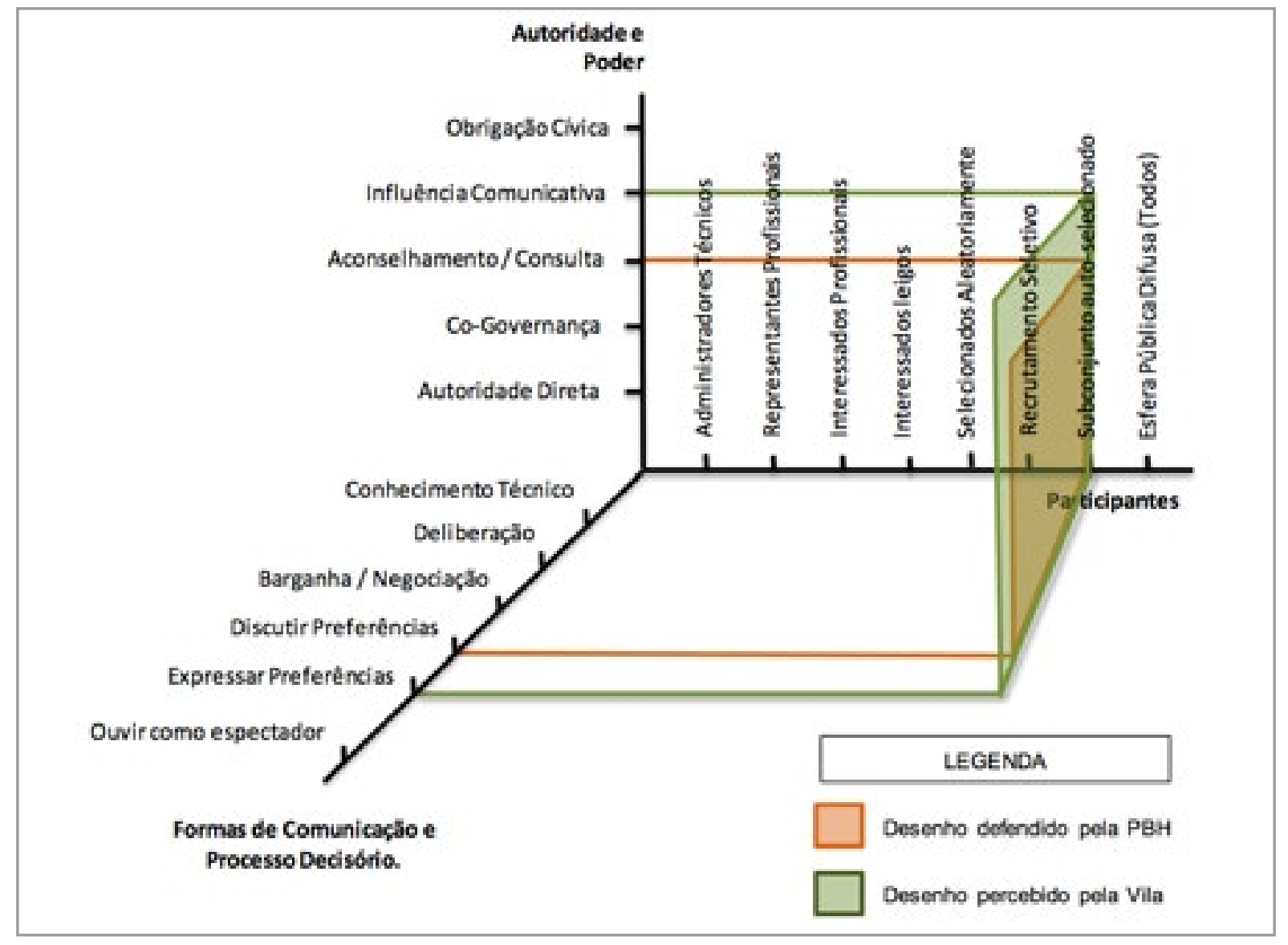

Fonte: Elaborada pela autora.

A partir dessas figuras, ratificamos que a SMAGC congrega instâncias com diferentes desenhos institucionais, que variam desde formas mais agregadoras de participação até formas mais exclusivas, mas também de instâncias que envolvem maior ou menor concretude das questões a resolver, maior ou menor proximidade com os problemas sociais, maior ou menor compromisso com as decisões, maior ou menor resposta aos cidadãos. 0 Nudec, dentre as três instâncias, é a que apresenta oportunidades mais efetivas para os cidadãos influenciarem a tomada de decisão do poder público, bem como de reconhecimento desses atores como sendo capazes de propor ações concretas e fidedignas à realidade local, gerando certa integração de objetivos e conferindo legitimidade à participação. No entanto, por ter um viés mais concreto e executivo, 0 núcleo cria, paradoxalmente, maiores chances de circunscrevê-los à institucionalidade.

JáaCLSVJ e a Comforça, que apresentam arranjos institucionais semelhantes, não implicam ações imediatas tão concretas. Seus desenhos evocam uma noção de accountability (como responsividade), ou seja, não desenvolvem uma discussão aprofundada para solução de problemas, mas se preocupam em responder aos questionamentos dos participantes. Por possibilitarem um menor debate entre as partes, essas instâncias, consequentemente, diminuem o potencial de influência mais imediata que os cidadãos podem ter sobre uma política pública.

Outra questão importante que os cubos mostram é a conformidade das percepções sobre a seleção de quem participa. Em todos os três desenhos a seleção de participantes é uma dimensão em que a visão oficial e a cotidiana coincidem, 0 que nos revela que os cidadãos que desejam participar dessas instâncias não têm outra alternativa (ou não percebem que tem) a não ser se adequar à forma com que é feita a escolha de quem participa. Também percebemos que, quanto mais restrita a forma de selecionar os participantes, mais qualificadas são as discussões que acontecem nos fóruns e maior é a probabilidade de essa discussão influenciar a implementação de uma política pública no nível local - situação que o desenho do Nudec comprova. 
Após se adequarem às regras de seleção, os cidadãos ainda se deparam com as normatividades que regem o modo de tomada de decisão, o que consequentemente afeta o seu potencial de influência nas políticas públicas. Contudo, 0 maior problema não são as normas em si, mas sim a morosidade que causam. Cansadas de levarem meses para ter seus problemas resolvidos pelos fóruns de participação, as lideranças da Vila Jardim do Vale acabam apelando para estratégias de embate aos desenhos institucionais que interferem tanto na dimensão da tomada de decisão quanto nas suas formas de empoderamento. Assim, se o fórum se propõe uma discussão das questões para solução de problemas, mas o que ocorre é que ele apenas ouve a comunidade e não realiza nenhuma interferência, esta recorre à negociação com o Poder Legislativo ou a estratégias de ação direta, de modo que seja efetivamente tomada uma decisão que provoque resultados concretos.

\section{CONSIDERAÇÕES FINAIS}

Após esse percurso de análise, chegamos a alguns apontamentos importantes sobre as implicações da proposta de gestão compartilhada de Belo Horizonte e as articulações comunitárias que emergem nesse contexto, conforme elencamos a seguir.

1) Multiplicidade de desenhos institucionais participativos - Aqui destacamos a tentativa da Prefeitura de Belo Horizonte de congregar todas as formas de participação existentes na cidade sob a égide de um mesmo órgão. 0 principal dilema que emerge dessa iniciativa é a multiplicidade de desenhos institucionais participativos com que a SMAGC e os cidadãos têm que lidar. A análise dos desenhos institucionais das três instâncias participativas que consideramos mostra empiricamente essa diversidade de arranjos. Essa diversidade pode causar constrangimentos à participação, mas também pode possibilitar a participação de uma maior diversidade de públicos.

2) A incidência dos desenhos institucionais sobre a organização da comunidade como público - Ao olharmos para nosso caso empírico, percebemos que a Vila Jardim do Vale busca se articular interna e externamente para participar das diversas instâncias que a prefeitura contempla, de modo a tentar influenciar as decisões que são tomadas nesses fóruns, tendo em vista a melhoria das condições de infraestrutura e da qualidade de vida local. A história da Jardim do Vale evidencia pelo menos três elementos que são necessários para que uma comunidade possa participar e seja capaz disso: estar em um território ocupado legalmente; adequar-se às regras das instâncias; mobilizar-se interna e externamente, realizando parcerias para conseguir quantidade e qualidade nessas instâncias.

3) Diferentes expectativas sobre os desenhos institucionais - Aquilo que a Prefeitura de Belo Horizonte postula em seu discurso como sendo o arranjo institucional de uma instância, gera expectativas naqueles que dela participarão. Contudo, ao participarem, os cidadãos acabam tendo uma percepção diferente daquilo que julgavam ser a dinâmica da instância. Essa diferença de percepção, como demonstrou a análise comparativa da visão oficial e da visão cotidiana dos desenhos institucionais da CLSVJ e da Comforça, normalmente está associada às dimensões da tomada de decisão e do potencial de empoderamento que os fóruns permitem. Isso nos diz que a comunidade tem uma grande expectativa em influenciar a tomada de decisão por meio dos fóruns participativos, mas, em algumas situações o que acontece é que as regras desses fóruns não possibilitam que ela influencie do modo que gostaria, o que gera uma insatisfação. Mesmo que os fóruns não resultem em ações concretas, os cidadãos esperam pelo menos uma resposta do poder público, esperam que ele seja accountable.

4) Diferentes formas de influência sobre as decisões circunscritas aos desenhos institucionais e para além deles - Os desenhos institucionais das instâncias participativas que surgem do processo de gestão compartilhada são compostos de 
muitas variáveis, podendo ser combinados de muitos modos diferentes. Cada modalidade coloca possibilidades e limites distintos à interação e à interlocução com os cidadãos, o que reflete no potencial de influência nas políticas públicas que eles podem ter. As regras desses desenhos criam oportunidades ou constrangimentos a certas ações, conformando o processo de comunicação pública e a organização da sociedade civil.

Durante nossa análise, percebemos que, embora cada instância tenha suas peculiaridades e ofereça oportunidades diferentes de a comunidade influenciar em suas decisões, todas as três recaem no mesmo problema: reduzir a complexidade das relações comunitárias à representação institucionalizada. Todavia, a institucionalização tende a fechar padrões de ação, tende a uma formalização, o que contrasta com as relações de tipo comunitário - mais informais, dinâmicas e abertas. Quando os públicos se conformam para agir na institucionalidade, boa parte de seu potencial de influência fica restrito aos limites das instâncias, o que os deixa sujeitos a suas temporalidades e à "boa vontade". Paradoxalmente, essa organização também pode aumentar a influência dos públicos, já que pelas vias formais o reconhecimento institucional tende a aumentar esse poder de influência até certo ponto. Contudo, essa lógica é sempre complexa para que os públicos lidem com ela (o que escapa aos limites desta pesquisa).

\section{REFERÊNCIAS}

AVRITZER, Leonardo. Instituições participativas e desenho institucional: algumas considerações sobre a variação da participação no Brasil democrático. Campinas: Opinião Pública, Campinas (SP), v. 14, n. 1, p. 43-64, jun. 2008.

BRANDÃO, Elizabeth Pazito. Conceito de comunicação pública. In: DUARTE, Jorge (Org.). Comunicação pública: estado, mercado, sociedade e interesse público. São Paulo: Editora Atlas, 2009.

COSTA, Frederico Lustosa da. A que serve a noção de gestão compartilhada? In: CONGRESO INTERNACIONAL DEL CLAD SOBRE LA REFORMA DEL ESTADO Y DE LA ADMINISTRACIÓN PÚBLICA, XIV, Salvador, BA, Brasil, 27-30 oct. 2009. Disponível em: <http://siare.clad.org/fulltext/0063267.pdf>. Acesso em: 11 fev. 2014.

DRYZEK, John S. Deliberative democracy and beyond: liberals, critics, contestations. New York: Oxford University Press, 2000.

DUARTE, Jorge. Comunicação pública. Disponível em: <http://www.jforni.jor.br/ forni/files/ComPúblicaJDuartevf.pdf>. Acesso em: 30 set. 2011.

ESTEVES, João P. Sociologia da comunicação. Lisboa: Fundação Calouste Gulbenkian, 2011.

FUNG, Archon. Varieties of participation in complex governance. Public Administration Review, Chicago, IL, v. 66, p. 66-75, 2006.

GESTÃO COMPARTILHADA. Apresentação. Disponível em: <http://gestaocompartilhada.pbh.gov.br/apresentacao>. Acesso em: 2 fev. 2014.

KOÇOUSKI, Marina. Comunicação pública: construindo um conceito. In: MATOS, Heloiza (Org.). Comunicação pública: interlocuções, interlocutores e perspectivas. São Paulo: ECA-USP, 2012. p. 71-96. 
KUNSCH, Margarida M. Krohling. Comunicação pública: direitos de cidadania, fundamentos e práticas. In: MATOS, Heloiza (Org.). Comunicação pública: interlocuções, interlocutores e perspectivas. São Paulo: ECA-USP, 2012. p. 13-29.

MINISTÉRIO DA SAÚDE. Manual de orientações para contratação de serviços no Sistema Único de Saúde. Brasília: 2007.

NOLÊTO, Eusébia de Araújo Pereira. Gestão compartilhada: autonomia da escola. II In: CONGRESSO CONSAD DE GESTÃO PÚBLICA, II, Brasília, 2009.

PBH - Prefeitura Municipal de Belo Horizonte. Boletim Gestão compartilhada: ampliando a participação popular em Belo Horizonte, v. 1, 2011.

TORRECILHA, Maria Lúcia. A gestão compartilhada como espaço de integração na fronteira Ponta Porã (Brasil) e Pedro Juan Caballero (Paraguai). Tese (Doutorado em Geografia Humana) - Faculdade de Filosofia, Letras e Ciências Humanas, Universidade de São Paulo, São Paulo, 2013.

WEBER, Maria H. Na comunicação pública, a captura do voto. Logos 27: Mídia e Democracia, a. 14, p. 21-42, 2. Sem. 2007.

ZÉMOR, Pierre. La communication publique. Paris: PUF, 1995.

Artigo recebido em 5.8.2015 e aprovado em 3.10.2015. 